\title{
Passage kinetics of internal and external markers in lactating dairy cows
}

\author{
S. Ahvenjärvi ${ }^{1,3}$, A. Vanhatalo ${ }^{1}$, A.N. Hristov ${ }^{2}$ and P. Huhtanen ${ }^{1}$ \\ ${ }^{1}$ MTT Agrifood Research Finland, Animal Nutrition \\ FIN-31600 Jokioinen, Finland \\ ${ }^{2}$ Department of Animal and Veterinary Science, University of Idaho \\ Moscow, 83844-2330, USA
}

\begin{abstract}
Particle passage kinetics in dairy cows was assessed using acid detergent fibre (ADF) associated ${ }^{15} \mathrm{~N}$ as an internal marker and chromium $(\mathrm{Cr})$ mordanted grass silage, ytterbium ( $\mathrm{Yb}$ ) labelled grass silage and dysprosium (Dy) labelled faecal particles as external markers. Kinetic parameters were estimated using two-compartment models assuming gamma time-dependent (G3) passage rate in the first compartment and age-independent (G1) in the second compartment. Parameter estimates were consistent between $\mathrm{ADF}-{ }^{15} \mathrm{~N}$ and $\mathrm{Cr}$, but for $\mathrm{Yb}$ and $\mathrm{Dy}$ the total mean retention time and retention time in the age-independent compartment was shorter.
\end{abstract}

KEY WORDS: passage kinetics, markers

\section{INTRODUCTION}

Modelling of ruminal nutrient degradability requires quantitative information on passage kinetics of digesta from the reticulo-rumen. Passage kinetics of soluble substrates follows first order kinetics, whereas particulate matter passage rate is dependent on the physical characteristics of particles. Ingested particles have a low probability of entering the omasal canal before they have been comminuted smaller than a critical size (Poppi et al., 1981). In addition, physical entrapment within particulate matter raft may decrease particle passage rate (Poppi et al., 2001). Particle passage kinetics has been studied using external markers labelled onto feed particles. External markers have been criticized for altering the physical characteristics of particles (Ehle, 1984) or that they may dissociate from the

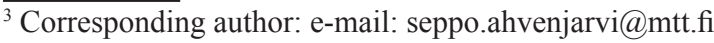


labelled material and associate to small particulate matter and microbes (Combs and Satter, 1992). Huhtanen and Hristov (2001) assessed particle passage kinetics using fibre-bound ${ }^{15} \mathrm{~N}$ as an internal marker. Theoretically, use of internal markers might overcome the problems associated with external markers. The current study compared the passage kinetics of $\mathrm{ADF}-{ }^{15} \mathrm{~N}$ to that of $\mathrm{Cr}, \mathrm{Yb}$ and $\mathrm{Dy}$.

\section{MATERIAL AND METHODS}

Particle passage rate was studied on four multiparous Ayrshire dairy cows of $660 \mathrm{~kg}$ (SD 40.1) liveweight. Cows were 96 days in milk (SD 27.0), produced $33.0 \mathrm{~kg} / \mathrm{d}$ (SD 5.98) of milk and consumed 14.8 (SD 0.97) and $8.9 \mathrm{~kg} / \mathrm{d}$ (SD 0.11) of grass silage and concentrate DM, respectively. Timothy grass grown on a field on clay soil was fertilized with ammonium sulphate (Isotec Inc. Miamisburg, OH; $10 \%{ }^{15} \mathrm{~N} / \mathrm{N}$ ) at a rate of $100 \mathrm{~kg} \mathrm{~N} / \mathrm{ha}$. Grass was harvested when $62 \%$ of ears had emerged, coarsely chopped using a laboratory scale chopper, wilted until dry matter concentration of $220 \mathrm{~g} / \mathrm{kg}$ and then preserved in plastic silos $(1.6 \mathrm{~kg} \mathrm{DM}$ each) with formic acid applied at a rate of $5 \mathrm{~L} / \mathrm{ton}$.

Chromium was mordanted onto grass silage as described by Udén et al. (1980) modified such that $\mathrm{Cr}$ concentration was $24 \mathrm{~g} / \mathrm{kg}$ DM. Grass silage was labelled with $\mathrm{Yb}$ by incubation in ytterbium acetate solution (Dasico a/s, Birkerod, Denmark) for $48 \mathrm{~h}$ at room temperature, followed by removal of loosely bound element with distilled water adjusted at $\mathrm{pH} 4.5$ with acetic acid. Faecal particulate matter was collected from each animal, washed with hot water and laundry detergent, then labelled with dysprosium $\left(\mathrm{DyCl}_{3} \cdot 6 \mathrm{H}_{2} \mathrm{O}\right.$; Sigma-Aldrich, Corp., St. Louis, MO, USA) similar to the procedure described for $\mathrm{Yb}$.

Passage kinetic parameters were estimated using two-compartment models assuming gamma time-dependent $\left(G_{n}, n=2-4\right)$ passage rate in the first compartment and age-independent (G1) in the second compartment (Pond et al., 1988). Currently, parameter estimates using G3G1 model have been reported on the basis of least residual sums of squares.

\section{RESULTS}

Estimates of kinetic parameters were consistent between $A D F-{ }^{15} \mathrm{~N}$ and $\mathrm{Cr}$, whereas $\mathrm{Yb}$ and Dy indicated significantly different passage kinetics (Table 1). Highest total mean retention time was estimated for $\mathrm{Cr}$ and $\mathrm{ADF}-{ }^{15} \mathrm{~N}$. Total mean retention time of $\mathrm{Yb}$ was significantly smaller and use of Dy resulted in lowest estimates. 
Table 1. Effect of marker on passage kinetic parameters estimated based on excretion patterns in faeces

\begin{tabular}{lccccc}
\hline \multirow{2}{*}{ Item } & \multicolumn{4}{c}{ Marker } & \multirow{2}{*}{ SEM } \\
\cline { 2 - 5 } & ADF- ${ }^{15} \mathrm{~N}$ & Chromium & Dysprosium & Ytterbium & \\
\hline$\tau, \mathrm{h}$ & $6.4^{\mathrm{b}}$ & $6.3^{\mathrm{b}}$ & $8.1^{\mathrm{a}}$ & $5.8^{\mathrm{b}}$ & 0.46 \\
CMRT1, h & $13.1^{\mathrm{b}}$ & $15.9^{\mathrm{ab}}$ & $7.6^{\mathrm{c}}$ & $19.3^{\mathrm{a}}$ & 1.27 \\
CMRT2, h & $25.7^{\mathrm{a}}$ & $24.1^{\mathrm{a}}$ & $13.1^{\mathrm{b}}$ & $13.9^{\mathrm{b}}$ & 1.76 \\
CMRT, h & $38.8^{\mathrm{a}}$ & $40.1^{\mathrm{a}}$ & $20.7^{\mathrm{c}}$ & $33.2^{\mathrm{b}}$ & 0.77 \\
TMRT, h & $45.2^{\mathrm{a}}$ & $46.3^{\mathrm{a}}$ & $28.8^{\mathrm{c}}$ & $39.0^{\mathrm{b}}$ & 1.02 \\
\hline
\end{tabular}

a, b, c means within a row without a common supercript letter differ significantly $(\mathrm{P}<0.05)$

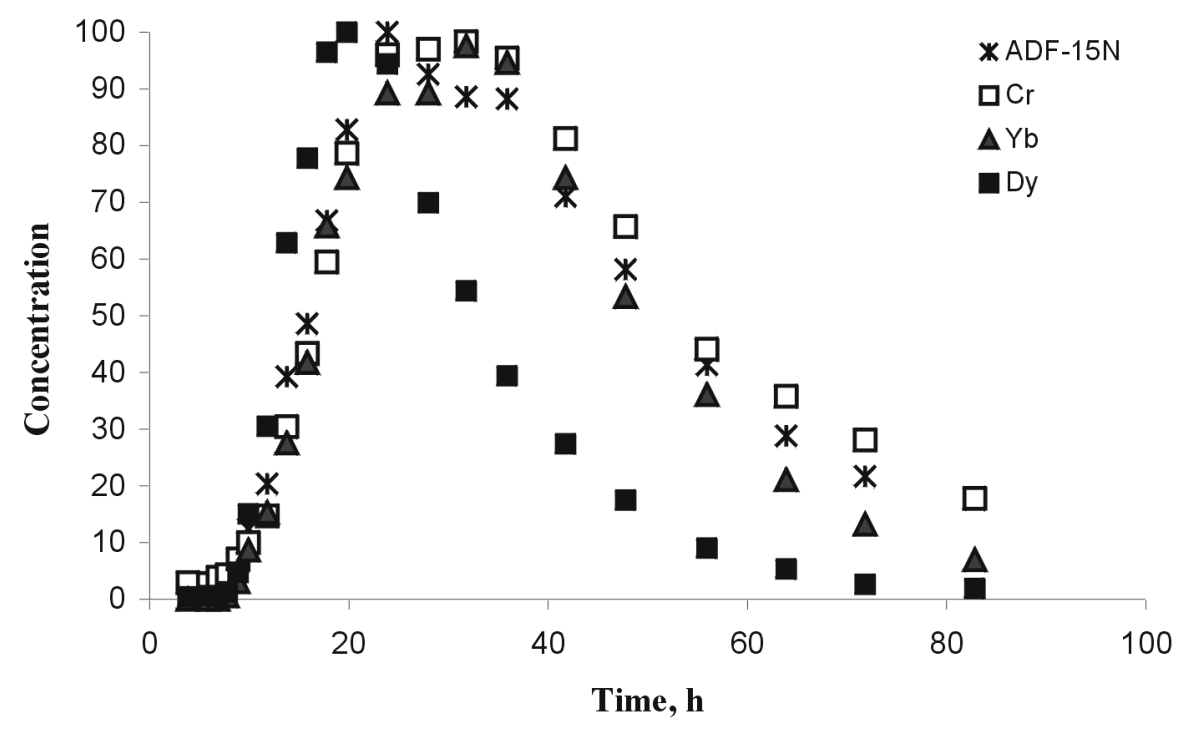

Figure 1. Marker concentration in faeces expressed as percentage units of maximum concentration

Compared with $A D F-{ }^{15} \mathrm{~N}$ the total mean retention time of $\mathrm{Yb}$ and Dy was $6.2 \mathrm{~h}$ and $16.4 \mathrm{~h}$ shorter, respectively. Retention time in the age-dependent compartment was highest for $\mathrm{Yb}$, intermediate for $\mathrm{Cr}$ and $\mathrm{ADF}-{ }^{15} \mathrm{~N}$ and lowest for Dy. Retention time in the age-independent compartment was higher for $\mathrm{Cr}$ and $\mathrm{ADF}-{ }^{15} \mathrm{~N}$ compared with $\mathrm{Yb}$ and $\mathrm{Dy}$. Shorter retention time of $\mathrm{Yb}$ in the ageindependent compartment is reflected in a steeper slope of the descending part of marker excretion curve in faeces (Figure 1). 


\section{DISCUSSION}

Current estimates of CMRT and TMRT based on ADF- ${ }^{15} \mathrm{~N}$ are similar to those observed by Huhtanen and Hristov (2001) in Holstein cows in late lactation (39.3 $\mathrm{h}$ and $47.0 \mathrm{~h}$, respectively). Shorter retention time estimated with $\mathrm{Yb}$ compared with $\mathrm{ADF}^{-15} \mathrm{~N}$ is probably explained by dissociation of rare earth element from originally labelled material (Combs and Satter, 1992). Differences between $\mathrm{Yb}$ and Dy are attributed to smaller particle size and lower digestibility of faecal particles compared with grass silage.

\section{CONCLUSIONS}

Use of $\mathrm{ADF}-{ }^{15} \mathrm{~N}$ and $\mathrm{Cr}$ resulted in similar passage kinetics, whereas the compartmental retention time was underestimated using $\mathrm{Yb}$.

\section{REFERENCES}

Combs D.K., Shaver R.D., Satter L.D., 1992. Retention of rare earths by hay particles following incubation in fresh or autoclaved rumen fluid. J. Dairy Sci. 75, 132-139

Ehle F.R., 1984. Influence of feed particle density on particulate passage from rumen of Holstein cow. J. Dairy Sci. 67, 693-697

Huhtanen P., Hristov A.N., 2001. Estimating passage kinetics using fibre-bound $15 \mathrm{~N}$ as an internal marker. Anim. Feed Sci. Tech. 94, 29-41

Moore J.A., Pond K.R., Poore M.H., Goodwin T.G., 1992. Influence of model and marker on digesta kinetic estimates for sheep. J. Anim. Sci. 70, 3528-3540

Pond K.R., Ellis W.C., Matis J.H., Ferreiro H.M., Sutton J.D., 1988. Compartment models for estimating attributes of digesta flow in cattle. Brit. J. Nutr. 60, 571-595

Poppi D.P., Minson D.J., Ternouth J.H., 1981. Studies of cattle and sheep eating leaf and stem fractions of grasses. III. The retention time in the rumen of large feed particles. Aust. J. Agr. Res. 32, 123-137

Poppi D.P., Ellis W.C., Matis J.H., Lascano C.E., 2001. Marker concentration patterns of labelled leaf and stem particles in the rumen of cattle grazing bermuda grass (Cynodon dactylon) analysed by reference to a raft model. Brit. J. Nutr. 85, 553-563

Udén P., Colucci P.E., Van Soest P.J., 1980. Investigation of chromium, cerium and cobalt as markers in digesta. Rate of passage studies. J. Sci. Food Agr. 31, 625-632 